\title{
Global Retailers and Corporate Responsibility
}

\author{
Cosetta Pepe*
}

\begin{abstract}
Consumers and companies are paying more attention to responsible behaviour. What is more, the percentage of consumers who state they are ready to abandon a brand for environmental reasons has grown. Companies also perceive the value of responsibility to the environment and society.

Even in areas where these issues have become commonplace (primarily in the Anglo-American world), consumers tend to support the problem much more in their statements than in their actual purchasing behaviour.

Where retail companies are concerned, the acceptance of responsibility to the environment and to society is reflected in a number of motivations. First of all, the possibility of distinguishing themselves from the competition, which is the element most perceived by both mainstream and specialist companies. This is true in the food sector above all and in fields where the risk of accidents is greatest. Another motivation may be the fact that they could be eligible for ethical investment funds, particularly in the USA.
\end{abstract}

Keywords: Corporate Responsibility; Retailing; Supply Chain Economics; Retail Marketing; Global Corporations; Global Markets; Sustainable Development; Fair Trade

\section{Responsibility and Values in Evolving Business-Environment Relations}

Today, in some companies and sectors in particular, the issue of 'corporate responsibility' is the new theatre of competitive confrontation. Attention is focused on an extended concept of responsibility, the fruit of a general evolution of the 'values' that underpin relations between business and environment. They are characterised by economic, social and environmental values, and above all - in their most advanced form - by a philosophy that shifts the focus of the analysis to the relationship between production, consumption and culture, highlighting the deepest link: 'the traditional approach reflects the idea that markets are primary, ...but this is mistaken because companies created the culture first and then the markets, ...so the utility of the markets must be linked to the intimate depth of the culture' (Rifkin, 2003)

\footnotetext{
*Full Professor of Management, University of Rome-Tor Vergata (cosetta.pepe@ uniroma2.it)
}

Cosetta Pepe, Global Retailers and Corporate Responsibility, Symphonya. Emerging Issues in Management (symphonya.unimib.it), n. 1, 2003, pp. 55-71 
For the company it is therefore a question not only of overcoming a concept of responsibility linked to the maximisation of the capital invested by the shareholders, but also of going beyond the simple act of answering for its performance to the various types of stakeholders, and creating the conditions so that all the parties involved, both directly and indirectly, can be part of the same 'culture' of production, the market and the territory.

The issue therefore involves not only corporate responsibility, but also that of the other parties involved. We can consider the responsibility of consumers - regarding the many aspects of responsible consumption related to the quality of the products, the environmental and social balance, and awareness of the gap between the southern and northern hemispheres - and the responsibility of the various institutions, national and international, public and private, that must provide the orientation, support and, above all, control and certification that these responsibilities are actually exercised.

However, it is not easy to estimate the real degree of sensitivity to this issue and the effective dissemination of the commitment on this front; and it is just as difficult to understand the nature, motives and roots of this renewed attention to the problem. It is possible to have two opinions in this regard, which correspond to two types of behaviour on the part of the companies. On one hand, that the re-emergence of the issue of responsibility derives from an improved perception of the complexity of the relationship between company and environment and a greater capacity to deal with it - a circumstance that would express 'active' behaviour on the part of the interested companies. On the other hand, that the reason lies in the need for companies to 'react' to the deterioration of this relationship (Nicholls, 2002), caused both by objective motives (pollution, food risks, new forms of exploitation, increased inequality), and by subjective elements, in particular consumers' growing sensitivity and the ever growing initiative of the various social players who promote awareness of the problem, sustaining or directly achieving alternative economic processes - as in the case of fair trade - that are more in tune with the principles of balanced development.

In any case, the framework of analysis regarding the extended concept of responsibility reveals a sum of circumstances that are not dissimilar to those that induce companies to correct, adapt or even reformulate their own strategies and policies. Faced with the changes taking place on the markets, companies must introduce more or less radical innovations - in one or more areas of the company to respond to particular needs on the part of consumers, to various competitive dynamics, and to new opportunities and conditioning. These innovations - studied or just suggested by the behaviour of other players (consumers, competitors, external organisms) - are nonetheless always designed to improve positioning, development and performance: positive values for the company, that are consistent with its 'genetic codes' and with the language that decodes and expresses them.

Ethics, social aspects and equilibrium in the territory are issues that companies have always had to deal with: they are occasionally considered in conflict with the institutional goal of maximising the capital invested or, in the broader, medium to long term, considered and taken on board as necessary to the company's survival. In the manufacturing culture, or even in the culture of consumption, attention was concentrated on efficiency/effectiveness and on the quality/convenience ratio; the remainder was complementary and all the elements in play, whether negative or 
positive, were attributed to the prevailing orientation. What is being outlined today, on the other hand, is a sum of values that form a system, occasionally questioning corporate balances but also revealing itself as a precious competitive lever for those who know how to exploit it.

The issue of corporate responsibility - which is referred to internationally by the acronym CSR (Corporate Social Responsibility) - is 'contaminating' the social and economic environment, being forced on many companies, often just as a simple element of discussion and image, but increasingly as a necessity or a stimulus to some form of change.

This is not the place to table a debate comparing corporate behaviour that is 'authentically' motivated by ethics with behaviour that 'uses' ethics to pursue the classic corporate goals. We are more interested in underlining that the various aspects of Corporate Social Responsibility follow and evolve in line with a cultural evolution that affects all the players in the environment-market, who are interactive and mutually conditioned, as they would be by any other type of change.

The problem is not therefore to brand the company's actions as more or less moral, but to see the extent to which it is involved, the tools it uses to deal with or to 'embrace' the problem of CSR and, above all, which real transformation all this can bring to the corporate culture, management principles, economic development and value distribution.

\section{Sustainable Development, Supply Chain Economics and the Territory}

From a minimum to a maximum degree of involvement: the gamut of meanings given to the term responsibility is not only broad and composite, but above all it now covers a chain of economic parties: to be precise, the chain of parties linked to a single production-distribution-consumption cycle, inspired by ethical, social and environmental values that transcend the operating environment of individual companies and extend to the entire supply chain.

The concept that expresses the various aspects of responsibility and implicitly involves all the parties that make up the product chain is the concept of 'sustainable development'. This expression sums up the three basic dimensions of the problem: protection of the environment, respect of human rights and equity in the distribution of value, even referred to the needs of the communities and territories that are involved at various stages of the cycle. In this conception, the 'vertical' development of the chain overlaps with the 'horizontal' development given by the community and the territory, which takes on a particular significance upstream and downstream.

Upstream of the supply chain, the local economic context, manufacturing techniques, labour conditions and the protection of the environment, all draw attention to a number of problems that must be managed with a territorial policy that invests a fair share of added value in its development. Downstream, where the product is placed on the end market, the company is strongly tied to the community with its range of products and services, but also because it promotes social values and philanthropy, consistent with the sensitivity of the context. The vicinity to the market obviously makes the issue of responsibility more complex, even in relation 
to the policy of the territory and the protection of the environment. On the other hand, consumers' awareness of the issue of economic solidarity links the company's activities with its roots, thus merging the two aspects.

Public and private institutions - in Italy the Ministry of Labour, in collaboration with Universities, Chambers of Commerce and Research Institutes - are implicated in the relationship between company and territory, at all levels of the supply chain, with activities that underline the importance of corporate responsibility for the competitiveness of companies and the Country-System.

The work of these institutions aims to overcome a weak approach to social responsibility, 'so that the resources that companies wish to dedicate to their territory can reach a critical mass and contribute to the achievement of a successful welfare society'. This covers the programmes that not only work to establish standards with which to monitor behaviour, but also envisage various incentives to encourage companies to invest in welfare in their territory.

$\square$ The proposal elaborated in this sense by the Italian Government aims to involve companies in the funding of welfare policies, in exchange for tax relief and privileged access to loans, in the context of collaboration between the public and the private sectors (Labitalia 2003). In an economy in which relations between companies are increasingly important, this stimulus from the outside world constitutes an incentive for the entire system, with an effect that extends upstream to the suppliers. The problems surrounding shared responsibility inside the chain must be analysed in light of the imbalance between the dimensions of the parties involved and their capacity for information, knowledge and control.

The strategic value of the entire supply chain is now so obvious that, in most cases, control of the individual stages of the process is combined with the need to control the entire chain, generally under the leadership of the strongest party, accompanied by greater or lesser degrees of collaboration from the other parties in the chain. So it is important to reconstruct the channels, analysing their structure and understanding the nature of the relationships established between the parties involved. In particular, in addition to the role of the manufacturer, we must take into consideration the role of the retailer, particularly when the latter has a strong capacity to involve the end consumer with its complex formula, and the capacity to activate supply chains that are completely governed, even if they are not directly owned in an integrated vertical structure.

\section{Focusing on Social Responsibility in Retailing}

The field of analysis chosen is the problem of the responsibility of marketing companies, particularly large retail companies, which, like the larger and more influential industrial companies, now control manufacturing and distribution chains, from a position of the 'stronger' and therefore also 'more responsible' entity. The complex nature of this responsibility is even clearer in the case of the 
large marketing company: relations with suppliers, which are often smaller, that have little control over the end market and increasingly tend to depend on the marketing company; the vicinity to consumers and the possibility of interpreting their needs and expectations not only with regard to consumption; strong integration in the territory with greater potential for integration and variety in the products offered and intervention than for an industrial company. There is substantial convergence in the behaviour and responsibilities of large manufacturing and retail companies that control the national and international supply chains, however, because the retail sector is newer and less investigated, we want to grasp its specificity and to contribute to the broader debate about corporate responsibility from their viewpoint and with their language.

This reference to viewpoint and language is not casual: the position of the large retail company, the last link in the value chain, naturally encourages a broad view that takes in the entire sequence of stages and passages in the production and marketing of a product or service. The problem of giving transparency and therefore guarantees to the entire supply chain is expressed in terms of 'traceability'. The care given to the problem of traceability reflects the need for a global view of the processes, which can recreate itineraries in order to understand them, control them and, possibly, manage them autonomously or through a close chain of relations that stretch upstream, back to the parties and locations of the first stages of manufacture-cultivation-extraction-initial processing, guaranteeing the quality and overall balance of the components of the products, but also of the environmental, social and ethical values of the processes.

All the stages are completed and recognisable in the passage to the end user, and when the overall value is achieved, and they are all evidently important and necessary. The perspective of the person at the end of the chain is naturally more comprehensive, but also more demanding and balanced: the results of the manufacturing, retail and service activities all converge there, giving equal dignity to them all, demanding their visibility, coordination and optimisation.

At the final point of sale we find products, tangible and intangible needs, purchasing behaviour, lifestyles and individual and collective values that relate to each other, offering numerous possible different compositions that can correspond to as many supply formulae. Retail marketing thus finds nourishment to strengthen and renew itself, multiplying the potential for positioning and playing on new elements. But it is not only a question of products and image: unlike an industrial company, a marketing company plays with a complex formula of products-services, the liveability of a place, and the pleasure of an experience that is not only a purchasing experience. The relationship with the clientele is more direct and investing in fomenting loyalty at the point of sale is safer and more effective today than investing in the product brand.

Certain aspects of the experience of the most advanced marketing companies are more striking, where the issues of responsibility and sustainable development are concerned:

- the relationship between the type of format - and relative size - and the way the issues of ethical and environmental values are developed and exploited in terms of retail marketing and relative positioning on the market; 
- highlighting the correlation between the assumption of these values and the problem of the control of the chain, and therefore its 'traceability'; the problem is managed by creating dedicated circuits, which are lean and strongly focused on decision-making; or by linking up with the 'alternative' Fair Trade circuits, with the difficulty of adapting its management to the strict rules that govern the latter, but at the same time opening up real potential for the development of their products;

- the implications that the assumption of ethical, social and environmental values linked to sustainable development brings for retail marketing, which now has to manage a mix of 'products, services and values' using new tools and forms of communication, for which it must reinvent itself, respecting the intrinsic consistency, and trying to exploit the potential of relations with the clientele, in management - particularly that of personnel - and in more general relations with society and the territory.

\section{Corporate Responsibility and Sustainable Development: from the Market Niche to Mass Consumption}

As we have already seen for other processes of change and innovation in the field of retail marketing - in particular for technological innovation and internationalisation - the phenomenon initially affects small but highly specialist companies; greater dissemination and consolidated experience are impossible without the involvement of mainstream retailing.

However, for a relatively long period, involvement in terms of social, ethical and environmental values is limited to alternative and contrasting parties; the example is that of Fair Trade, which takes the form of importers of 'fair trade' products from the southern hemisphere that target the industrialised countries. The new entities are an expression of groups motivated by ethical and social values, and therefore outside the world of traditional trade and profit logics. The phenomenon began in the 1970s and developed a retail distribution system downstream, with its own sales outlets (the Botteghe del Mondo chain).

In the late 1980s there was a new consciousness on the part of society in the industrialised countries, encouraged by globalisation, the threat of increasingly serious damage to the environment, the growing gap between the northern and southern hemispheres, the growing maturity of consumers and diffidence towards the new economic liberalism. It revived the debate about corporate responsibility, taking it decidedly beyond the historical problems between investors and employers, towards a responsible relationship with society and the environment, upstream and downstream of the product.

Marketing companies are also involved and, as we have already seen in the industrial field, products inspired by ethical, social and environmental values differentiate the competition, occupying market niches with excellent potential for development. The phenomenon affects several commodity classes and even different formats.

Certain companies have begun to specialise. The sector most involved is the retail food sector, with organic and fair trade products. It has now extended to beauty and 
personal hygiene products, craftwork and clothing, adopting the same principles, while in the service field there is a growing supply of dedicated financial services (ethical and eco-friendly investment funds), and eco-tourism is also emerging. The combination of products inspired by ethical, social and environmental values with particular formats generates original, exclusive and often winning points of sale. In 2001, the Eurostaf study analysed the cases of several specialist US retailers (Whole Foods Market, Patagonia, Real Goods and Cleaner by Nature) operating respectively in the food sector (organic supermarkets), technical clothing with environmental implications, eco-friendly domestic systems (solar panels and similar articles), and eco-friendly dry cleaners. We should point out that in the cases examined the dominant environmental and eco-friendly aspects are often accompanied by social considerations (regarding working conditions) and solidarity (equal value distribution).

In mainstream retailing, on the other hand, the sale of products inspired by the values of sustainable development - without this being their prevailing or distinctive characteristic, as it is for specialist retailers - aims to express a general strategy that embraces several values, a new image that gives customers broader guarantees and takes on a commitment that goes beyond the marketing product, making the company 'a party in the democratic society, with a citizen's rights and duties'. This is the case of the highly internationalised retail chains, starting from giants like the British Tesco or French Carrefour.

The Anglo-Americans lead the field, followed by the French, while the Italian Coop is now also emerging, having launched an awareness programme some time ago. Historically, the process starts from environmental issues and extends to a broader, more complex vision of sustainable development. However, each group has its own itinerary, which can be very fast, at least in terms of taking the message and content of the communication on board, underlining the reactive and proactive capability of these companies.

This is the case with Carrefour, the French retail group, second in the world behind the US Wal-Mart chain, and present in 30 countries. Its aim is to be 'at the heart of society, rather than at the heart of the economy', orienting its entire organisation to adapt to various local contexts, simultaneously grasping the values that belong to everyone and focusing its mission on serving the consumer and accompanying the development of the middle class worldwide', guaranteeing 'modern, safe food trade, price and quality, and the smooth flows in collaboration with industrial companies'. An 'huge task in terms of economic development and social responsibility' (LSA 2002a). At the World Food Business Summit, the company Chairman and CEO said that 'retail companies must consider the changes that have taken place in society, incorporating an ethical dimension into their strategies, otherwise the risks will be very high and we will pay dearly for it in the future' (Bernard, 2003). Other speeches at the same Summit outlined the meaning of globalisation and retailers' new mission, particularly in the food industry: 'to create a new type of capitalism at the service of the vast market made up of populations with a low income', an enormous market space that offers opportunities for 
growth and social impact. According to some observers, the future international expansion of food retailers must reflect this prevailing philosophy: 'The wealthy population brackets only have limited potential for growth and development will therefore rely on winning the loyalty of low income customers, helping them to improve their situation until they catch up with middle class customers. But to achieve this goal, companies must pay much more attention to the problem of poverty.' (Cohon, Brugmann, 2003, p. 11).

Large companies are beginning to set up internal organisations to deal with the problem. In the outside world, dedicated institutions are emerging that promote and monitor this phenomenon, drawing up tables that rate companies by precise indices to reflect their commitment. The strategic importance of the phenomenon, even only in terms of image, is expressed through the creation of these internal and external structures that work to ensure respect of 'values': product quality, the social consequences of company operations, the effects on the environment and the humanitarian initiatives in the territory. 'The issues are always so vast and sensitive that these functions are always reserved for the top of the corporate organisation' (LSA 2002b), in the purchasing centre (the case of Opera in the Casino group, or Galec in the Leclerc group), or under company management (the case of Camif).

The organisation is even more complex in the Auchan company, with two central committees: one at management level and the other in the purchasing centre, in addition to regional committees, an 'environmental department', and one for relations with small companies. The German group Tengelmann, on the other hand, has created a specific organisational unit to manage environmental problems, the entire workforce receives suitable training in this field, and suppliers are invited to share these values. In order to formulate its CSR policies, Tesco created a committee that cut across all the functions, made up of senior managers, while Sainsbury's set up a committee of the heads of the individual areas involved in corporate responsibility (employees, community, customers, environment, investors, suppliers) which is supported by a smaller committee chaired by the head of External Relations, which meets three times a year to coordinate policies and draft CSR reports.

A number of new functions are therefore springing up, demanding new skills that can combine management with 'moral science', and find the best way to adapt to the new issues that consumers are sensitive to. The people who belong to these organisms are top managers - heads of marketing, managers responsible for purchasing particular products (for example, at Auchan, imported products and textiles), heads of marketing, quality, human resources and communications, but also external 'moral' personalities, university professors and members of humanitarian associations. Several large organisations have also founded their own associations and foundations (Camif Solidarité, Fondation Auchan). 
More in general, besides these dedicated organisms, there are special training initiatives that exploit the existing functions, for example those for purchasing managers and buyers regarding social audits and standards such as SA 8000. However, people generally presume that these problems should be managed by quality managers, both because they are already accustomed to certification procedures and used to handle precise constraints and processes that have to be respected (such as ISO 14001 environmental standards), and because they also know how to manage the changes that these new procedures trigger in the company.

However, new profiles will gradually have to be created, with a good level of general culture, familiar with the issues that these organisms have to handle, at a general and specific level. The activities of the large retail chains in the field of sustainable development must be linked to the outside world, and even the international market, in line with the policies of the UN (Global Reporting Initiative), the EU (Commission Working group on corporate responsibility), Eurocommerce, (the organism that represents operators in the retail trade sector at the European Commission), the ICC (the International Chamber of Commerce which has set up committees for the environment and the CRS), and the CIES-The Food Business Forum (including the Food Safety Working Group). Even certain NGOs (nongovernmental organisations) monitor the phenomenon. One of these is 'Ethique sur l'Etiquette', which publishes a collection of notes indicating the degree of involvement of the large French brands in social issues, with which all the large French brands have now established a dialogue. Other companies are commissioned to carry out social audits, such as Veritas, IGS and PricewaterhouseCoopers. In 2001, the latter conducted 10,000 social audits and predicted that the phenomenon was destined to grow, partly because new legislation now makes the publication of social reports mandatory (LSA 2002b).

\section{Traceability and Alternative Circuits}

CSR does not only imply strategic and organisational choices for the individual company but, as we have already seen, also entails paying considerable attention to activities all along the supply chain. This need for checks takes many forms:

- modifying the quality of relations with suppliers;

- introducing total checks, that are integrated upstream;

- in the encounter with chains that already focus strongly on the values of sustainable development (organic and fair trade).

The issue of the traceability of the chain must be seen in this context, because it is a tool for verification and a guarantee of the quality management systems, capable of recreating the product's history and progress with documented identification. The traceability of the supply chain is therefore linked both to cogent standards that aim to identify and correct possible problems related primarily to the protection and health of the individual-consumer (reg. EU 178/2002, EEC Dir. 2001/18, EEC Dir. $1760 / 2000$, Leg. Dec. 155/97), and to the possibility for companies to identify the responsibilities of each player involved in the product chain. 
In addition to being a technical management tool, for the correct monitoring of the entire chain, traceability systems also make it possible to identify and rationalise logistic flows, cutting running costs and intervening rapidly on causes of non-conformity, even guaranteeing the checking processes of weaker entities.

$\square$ Carrefour has 112 'quality chains' for fresh produce (33 for fish, 5 for cheese, and others for meat, fruit, vegetables, and organic products). A growing number of producers wish to sign contracts with the large stores, some of which are already responsible for organisms to protect products with controlled origin brands, and they are therefore already sensitive to the problems of the quality of the chain. On their part, large retailers commit the brand to a lasting supply relationship, which guarantees definite, agreed quality, the traceability of the supply chain and respect of the environment. In addition to boosting their image, they claim an attention to the territory that overcomes the traditional approach based primarily on prices.

The case of Carrefour represents behaviour typical of the major European and worldwide retail companies. All of them search for reliable partners, striving to put in place control systems, and now often certification systems, that can guarantee the quality and traceability of the product.

Tesco organises special conferences for its suppliers, where the latter can put questions to executives and be updated about market trends, consumers' needs and development strategies. The British company signed up to - and helped to draft - the 'Supplier Code of Practice' prepared by the Department of Trade and Industry. Sainsbury's, on the other hand, adopted its own voluntary code of commercial practice in 2000 ('Working with Suppliers').

In more advanced cases, companies certify respect of ethical and environmental values for a range of own-brand products. Own brand fair trade products join those of the Fair Trade circuits - usually under the importer's brand - which are increasingly reaching the end market through the retail chains.

\section{The Link with Fair Trade.}

Fair Trade is defined as the classic drop of water in an ocean: in 2001 total sales amounted to $€ 445.38$ million, representing $0.008 \%$ of world trade (Point de Vente, no. 850, May 9, 2001), with about 100 importers around the world, 532 production centres in 59 countries, and 30,000 dedicated retail outlets, 25,000 of which in Europe. However, its development may receive a decisive boost from large-scale retailing, which is now sensitive to and interested in committing itself to fair trade products. There are numerous examples, which already regard a range of products, especially classic colonial products like coffee, cocoa and bananas. 
$\square$ A dialogue has begun between the leading Fair Trade organisations and the large European retail chains. In the United Kingdom, the number of shops supplier ethical products and the range of fair trade products on offer are both growing. Sainsbury's now sells fair trade coffee in its supermarkets (The Grocer, 2003), in 2001 the Co-operative Group launched its own range of ethical products which is returning very good year-on-year growth, and now includes 81 fair trade products (Co-op, 2003), and in 2003 market leader Tesco - which accounts for $25 \%$ of sales in the British fair trade market - has doubled its assortment of fair trade products which now numbers 60, in various categories: from coffee to fresh fruit, and cut flowers from Kenya.

At the same time, the large retail chains support weekly marketing campaigns to raise awareness among consumers, such as the Fair Trade Fortnights which are supported by the leading food retail organisations (Mintel 2001).

$\square$ In France, the Dutch company Max Havelaar, one of the first of these organisations, which sells 5 tonnes of coffee in alternative shops and 500 in retail stores, signed an agreement with Monoprix in 1999 to distribute coffee under its own brand (17,000 packets per month), followed later by other products, with strongly growing sales and brand awareness. The other large French retail chains (Leclerc, Carrefour, Auchan, Intermarché and Cora) have also begun to introduce fair trade products into their ranges, occasionally under their own brand name (Auchan). They also play an active part in raising awareness of sustainable consumption among consumers, signing up to and promoting national thematic events like 'La quinzaine du commerce équitable'. In Italy, Coop was the first chain to introduce fair trade products under its own brand (Solidal label) with a range that extends from hot drinks to fruit juice and fresh fruit (bananas). Other European companies are also introducing fair trade products into their ranges: for example Ahold (Netherlands), Kesko (Finland), Tengelmann (Germany) and Sma-Auchan (Italy).

However, not all Fair Trade organisations accept the idea of promoting Fair Trade through the large retail chains, and the debate is still open. Several critical points remain in the alternative circuits, which can only be solved with the support of large retail chains. Fair trade products cost an average $10 \%$ more, a differential that can only be removed by increasing the quantities sold. It has been calculated that joining the retail system would reduce this difference to just $2 \%$. Another point highlighted is the high cost of the investment demanded of the points of sale in the alternative circuits, added to low profitability and limited visibility, factors that have the effect of limiting the expansion of the fair trade marketing network (PricewaterhouseCoopers 2001).

However it is widely accepted that the potential market for fair trade products is already very interesting, and that providing the consumer with more information through appropriate forms of communication, in parallel with a larger number of 
sales outlets, a vaster assortment and better visibility of fair trade products, will be decisive for their development.

\section{Retail Marketing and Sustainable Development}

In the more advanced markets - such as the UK - analysts already refer to a strategic response to the emergence of mass-market ethical consumerism (Nicholls, 2002), and the marketing policies that are most suitable for these new market developments. The debate focuses in particular on the legal aspects of retail marketing and the consumer's purchasing behaviour, which is directly linked to the supply of the sales outlet and therefore to the retailer's own strategies.

Many observers also claim that results can already be seen. They point to evidence of a positive correlation between transparent Corporate Social Responsibility and corporate performance (Balabanis et al. 1998), which underlines that the availability of ethical products is proving to be a factor of competitiveness. For the time being, this evidence appears to regard the retailers who have chosen to link their own specialisation to the values of sustainable development.

Where retail marketing policies are concerned, it seems that the size of the assortment is also very important for fair trade products: the problem is that of giving visibility to the new sector, extending and consolidating the market niche and exploiting the force of the new values in full. In the case of Whole Foods Market, the ethical and environmental values are not only applied to different classes of food products, but also to dietary and beauty products or personal care products, books and even clothing, although this is still marginal. This policy underlines the cohesive strength that the values of sustainable development can give, even to a product assortment that is relatively broad and not very consistent in terms of commodity class or use.

The concept of customer loyalty is also tending to grow as well as the means to achieve it. The customer's involvement can no longer be identified by the continuity of his purchasing behaviour, but rather by his more general support of values, ideals and programmes, expressed through participation in activities shared with other militant customers, to find information, develop and act in favour of the principles professed. Some of the cases examined, particularly that of the specialist chains of Patagonia and Real Goods, envisage various activities and rigour that scorns traditional methods of propaganda in favour of promotion by a very active clientele, suitably structured and organised, as well as the sense of belonging and the collaboration of employees. Every year employees consolidate their spirit of belonging by periods of work experience with NGOs all over the world, in line with the motto 'Actions Speak Louder than Words'. To organise its marketing, Patagonia takes its inspiration from the image and work of environmental associations, with strong, ideologically charged messages, political proposals and action to promote a proper movement to protect the environment. We could associate this strong involvement with the principles of experience marketing, which considers the experience and behaviour that derive from it as the fruit of the perception of the senses, emotions, and convictions generated by experiences with objects, places, social relations and group dynamics (Schmitt, 1999; Pine and Gilmore, 1999). 
However, specialist formats are still anchored to the intrinsic product quality which makes it possible to justify the high prices (even $25 \%$ higher), even better than the will to sign up to the professed cause. What is more, in most cases, traditional forms of communication and propaganda remain active, but they are dedicated to spreading not only knowledge of the products and services offered, but also the values, in fact a 'mix of values'. Guaranteeing respect of the environment and the quality of the product are often associated with the guarantee of ethics and equity in the management of the processes. A successful formula is exploited to the utmost and networks of sales outlets are created. In the case of Patagonia, these networks have also been internationalised, and it has 37 stores with an average size of about 450 square metres, and about 800 employees; Whole Food Market has 162 sales outlets in the USA and UK, with 27,000 employees; Cleaner by Nature, on the other hand, has 15 regional stores (in the Boston area), even in franchising. They employ methods such as mail order sales (the prevailing method for Real Goods) and Internet sales. Some operators sell exclusively online (GreenMarketplace.com, GreenHome.com, EcoMall.com, etc.).

Marketing inspired by sustainable development is not only the prerogative of specialist companies, but also of mainstream companies, which support it and to a certain extent associate it with traditional marketing. Many of the marketing levers in play (assortment, communication, merchandising) are therefore supported by the synergies and potential of retail marketing initiatives.

For other aspects, a certain amount of conflict may be generated, for example around the price differential that usually characterises these products, a factor that contrasts with the demands of mass consumption, particularly when development is slow, and companies are committed to a policy of price containment that has repercussions upstream on the supply chain. This pressure is in strong contrast with the very nature of supply chains that aim to increase and not to compress producers' margins, and which also have to meet not negligible logistical costs, due to low volumes and the fact that the sources of supply are located in remote areas served by poor communications structures. This is why some retailers are adopting a policy to contain their own margins on fair trade products in order to curb prices and develop the market, at least during the introduction stage.

Display and merchandising are also involved in the supply of these products, for the consistency of the formula and to maximise the synergies between the various marketing aspects. However, merchandising and display are often not effective. In fact, recently, to foster the growth of sales of fair trade products, some retailers have begun to set up sales outlets in dedicated sectors, although in many cases the good visibility of these products is not guaranteed, at least not to the extent that one might expect from products with such meaningful and complex messages to communicate and promote. In this regard, we could say that there is a certain prudence involved in giving visibility to the names of ethical products, almost for fear that there may be negative repercussions for products that do not have the same characteristics, particularly those from commercial brands, that are based on trust in the name rather than on knowledge and recognition of the product (Piacentini and others, 2000).

Retailers' uncertainty in conceiving marketing policies that are suitable for the new products, will be reflected in consumers' uncertainties. In particular, with regard to 
fair trade goods sold in the large British retail chain stores, it appears that the consumers willing to purchase fair trade products are still in a minority, and that the generic interest shown does not translate into a significant increase in sales. The limited assortment and the price differential also inhibit growth, as well as a natural resistance to any new product (Mintel 2001).

Some analysts (PricewaterhouseCoopers, 2001) suggest that the possibility of exploiting the potential of fair trade products on the extended market will depend on companies' ability to prick the conscience of consumers, but offering a broader assortment and lower prices.

On the other hand, even for mainstream retailers, quality has a decisive importance and the offer of new values cannot penalise the intrinsic character of products, which actually attract more attention because they offer a mix of tangible and intangible elements that are consistent with each other.

\section{Conclusions}

Analysing the issue of corporate responsibility in marketing companies, in particular in the most up-to-date and complex formula of Corporate Social Responsibility, throws light on a number of significant aspects, even if we do not yet have sufficient elements for a systematic investigation of the phenomenon. The experiences recorded, the available documentation and elements for analysis are still scarce, even if the problem of corporate social responsibility now has considerable resonance. This resonance does not correspond to a parallel, concrete commitment on the part of companies and their interlocutors. CSR issues break down into three main areas: environment and organic products (still prevalent aspects), shared ethical values (referred in particular to conditions of workers during production), equity and solidarity in the distribution of value along the chain and between capital and work. However they prove to be difficult to assimilate and can lead to behaviour that is often not consistent in companies, in consumers and in the framework institutions. Although, in terms of principles and of image and communications operations, they recognise the need to focus on the negative aspects of development and the problem of finding a remedy, actual behaviour and concrete policies reveal incongruences and lacunas.

On one hand, there is evidence that consumers and companies are paying more attention to responsible behaviour. In the United States, 66\% of consumers state that they trust companies that act in favour of a social cause. The approval rate increases (83\%) if companies take actions in which customers recognise values of particular importance or they are personally involved (Chain Store Age Executive, August 2000). What is more, the percentage of consumers who state they are ready to abandon a brand for environmental reasons has grown from $67 \%$ in 1996 to $70 \%$ in 2000 (Brandweek, February 2001). According to Censis, awareness of companies' responsible social behaviour is also growing in Italy. For $36.2 \%$ of interviewees, this commitment should be directed towards the environment and health, for $19.7 \%$ towards protecting working conditions and for $12.5 \%$ towards the promotion of initiatives in the social field (Labitalia.com). Companies also perceive the value of responsibility to the environment and society. Where Italy is concerned, according to an analysis conducted for the Minister of Welfare by Bocconi University in 
collaboration with Confindustria, $43 \%$ of companies predict an increase in this social commitment. The motivations are linked to performance. In fact, for almost all companies (90\%), there will be benefits in terms of image, while $76 \%$ are concerned with improving relations with the community, in other words it is an investment that is linked more specifically to relations with the territory (Labitalia.com).

On the other hand, even in areas where these issues have become commonplace (primarily in the Anglo-American world), consumers tend to support the problem much more in their statements than in their actual purchasing behaviour. Similarly, pronouncements by even the most committed companies claiming that strategies (and now even structures) should be based on the new principles, do not necessarily lead to consistence choices during the actual implementation stage. For example, we can see a certain prudence in following new directions, which are still considered too demanding in terms of costs and checks, and even too risky for the many promises that must be made and therefore kept.

Where retail companies are concerned, the acceptance of responsibility to the environment and to society is reflected in a number of motivations and potential that are the subject of growing attention and assessment by companies and consequently of studies conducted by observers of the phenomenon. First of all, the possibility of distinguishing themselves from the competition, which is the element most perceived by both mainstream and specialist companies, or that of promoting a positive image, constituting a store of trust with consumers who will be more inclined to forgive any mistakes. This is true in the food sector above all and in fields where the risk of accidents is greatest. Another motivation may be the fact that they could be eligible for ethical investment funds, particularly in the USA, where these are already a force to be reckoned with, but even in Europe, where they are also taking hold.

For specialist formats, which build up their identity around precise values, involving the territory and its social fabric, motivations can also be linked to the possibility of exploiting a precise identity and a strong relationship with the market, which can rely on motivated, loyal customers, on word of mouth, and on the support of external organisms, thus benefiting from lower investments in marketing. It is also possible to take the opportunity to involve a clientele from a higher income bracket, or at least one willing to pay more for products that respect certain values and to make salaried workers more loyal to the same values and to motivate them, offering a better quality of service to customers.

In the case of consumer packaged goods, therefore for mainstream groups, the problem of exploiting the potential of demand oriented to the values of sustainable development is more complex, the contradictions between the simultaneous offer of traditional products and products that are 'bearers of value' are evident. The problem of finding the right marketing ideas to reconcile the various elements in play is the most critical aspect and, at least in the medium term, possibly more difficult to solve than the problem of checking suppliers and the costs that need to be met to activate supply chains that respect the values professed. A solution that reduces the problem to the simple differentiation between products is not convincing, for many market segments and niches (fair trade, ethical products, with controlled quality, without GMOs, organic, eco-friendly, etc.), even if the first experiences take this direction. It is also significant that the same experiences already reveal a rapid tendency to contamination between the various elements. 
Own brand products - an expression of the consumer's trust - combine with one or more of these 'values', and fair trade products are often also organic, while those with controlled quality are also eco-friendly, and soon. It is a choice motivated by the synergies possible when the various elements are combined, from the search for greater force of impact, but also from a consistency that is imposed on the offer of values which cannot be overlooked once they have been mentioned. So it is difficult to think that this process of the gradual aggregation of values will tend to accentuate, combining with more traditional marketing elements: prices, intrinsic quality, design, assortment, services at the sales outlet, actions towards the outside world - as we have seen in the case of the U.S. chains mentioned above.

It seems that any future efforts must strive above all to maximise and respect consistency in the retail formula, which in turn must recompose the various aspects of the supply, monitoring the expected degree of awareness and consistency in customers' behaviour and taking for granted that, albeit in a discontinuous and fragmented way, consumers in advanced countries will be increasingly inclined to ask for a 'mix of products and values'.

The trade and circulation of goods would thus accompany the 'trade and circulation of values', in fact of new, nobler values - since there has always been a culture of values (positive and negative) in trade. Instead of thinking, negatively, of the risk of the instrumental use and merchandisation of values, we should think positively of their diffusion and a gradual sharing of tangible and moral well-being, in a range of action that is as broad as possible, profiting from the great apertures, but also from the folds of globalisation. It inevitably brings us to a territory where the boundaries of the investigation become less precise, and the tools of analysis must change. Instead of talking about fair trade products and responsible companies, we should start to talk about man's conscience.

\section{Bibliography}

Balabanis G., Phillips H., Lyall J., Corporate Social Responsibility and Economic Performance in top British Companies: Are They Linked?, European Business Review, vol. 98, n. 1, 1998, pp. 25 44.

Bernard D., Il commercio nell'era dello scetticismo, in Summit Mondiale del Commercio Alimentare, Barcellona 18-20 giugno, 2003, sintesi.

Cohon C, Brugmann J., Fare affari nella più grande economia mondiale: dar libero sfogo al potere di quattro miliardi di persone, una nuova impresa dopo l'altra, in Summit Mondiale del Commercio Alimentare, Barcellona 18-20 giugno, 2003, sintesi.

Co-op, Responsible Retailing Initiatives, CWS Publication, 2003.

Donalson T., Dunfee W., Business Ethics and Social Contract, Harvard Business School Press, 1998.

Eurocommerce , How CSR Initiatives Can Improve Quality in Employment in the Commerce Sector, in Conference Proceedings, Brussels 4-5 November, 2003.

Eurostaf, Le développement durable dans la distribution, ed. Eurostaf, Paris, 2001.

Rifkin J., Riuscire nell'era dello scetticismo, in Summit Mondiale del Commercio Alimentare, Barcellona 18-20 giugno, 2003, sintesi. 
Jacoby N. H., Corporate Power and Social Responsibility, Mac Millan, New York, 1973.

Jones P., Comfort D., Hillier D., Retailing Fair Trade Food Products in the UK, British Food Journal, vol. 105, n. 11, 2003, pp. 800-810. http://dx.doi.org/10.1108/00070700310511591

Labitalia, Responsabilità sociale: intesa tra Welfare e Unioncamere, in Labitalia.com, 27 novembre 2003.

LSA, Le commerce équitable a besoin de la grande distribution, LSA, n. 1721, 2001, pp. 38.

LSA, Savoir manoeuvrer avec une très grande réactivité, LSA, n. 1786, 17 octobre, 2002a, p. 64-67.

LSA, Le management étique, LSA, n. 1765, 25 avril, 2002b, pp. 60-61.

LSA, Dossier développement durable: les cinq chantiers de la distribution, LSA, n. 1825, 28 aout, 2003, pp. 48-54.

Marchés Tropicaux, Les supermarchés s'interessent davantage aux produits 'équitables', Marchés Tropicaux, 6 avril 2001.

Mintel, Attitudes Towards Ethical Foods Survey, ed. Mintel, London, 2001.

Murris C., Dossier 'Entreprises éthiques'- La grande distribution audite ses fournisseurs étrangers, LE MOCI, n. 1551, 20 juin 2002, pp. 44-50.

Nicholls A.J., Strategic Options in Fair Trade Retailing, International Journal of Retail \& Distribution Management, vol. 30, n. 1, 2002, pp. 6-17. http://dx.doi.org/10.1108/09590550210415220

Péters S., Le commerce équitable séduit les distributeurs, Les Echos, 4 mai, 2004.

Piacentini M., MacFadyen L., Eadie D., Corporate Social Responsibility in Food Retailing, International Journal of Retail \& Distribution Management, vol. 28, n. 11, 2000, pp. 459-469. http://dx.doi.org/10.1108/09590550010356822

Pine J.B, Gilmore J.H., The Experience Economy, Harvard Business School Press, 1999.

Point de Vente, Carrefour, filières qualité tous azimuts, Point de Vente, n. 878, 21 janvier 2002.

PriceWaterhouseCoopers, Strong Growth Potential for the Fair Trade Market, Retail and Consumer Worlds, vol. 39, n. 1, 2001.

Retail Week, Retail People - Corporate Values Emerge as a Priority for CEOs, Retail Week, 26 april, 2002, pp. 1-2.

Retail Week, Corporate Responsibility - Big Business Shows a Caring Side, Retail Week, 5 april, 2002, pp. 1-4.

Schmitt B., Experiential Marketing: How to Get Customers to Sense, Feel, Think, Act and Relate to Your Company and Brands, The Free Press, New York, 1999.

The Grocer, Ethical Approach Finds Favour, The Grocer, 13 september, 2003, p. 55.

Whysall P., Ethics in Retailing, Business Ethics: A European Review, vol. 4, n. 3, 1995, pp. 150156.

http://dx.doi.org/10.1111/j.1467-8608.1995.tb00246.x

Whysall P., Ethical Relationships in Retailing: Some Cautionary Tales, Business Ethics: A European Review, vol. 7, n. 2, 1998, pp. 103-110. http://dx.doi.org/10.1111/1467-8608.00095

Whysall P., Addressing Ethical Issues in Retailing: a Stakeholder Perspective, International Journal of Retail \& Distribution Management, vol. 28, n. 11, 2000, pp. 19-28.

http://dx.doi.org/10.1080/095939600405992 